ROCZNIKI HUMANISTYCZNE

Tom LXVIII, zeszyt $11-2020$

DOI: https://doi.org/10.18290/rh206811-2

\title{
ALEKSANDER BEDNARSKI
}

\author{
TEXTS IN TRANSITION: \\ INTERMEDIALITY IN PEREDUR SON OF EFROG \\ AND CYNAN JONES'S BIRD, BLOOD, SNOW
}

\begin{abstract}
A b stract. This paper examines Cynan Jones's novel Bird, Blood, Snow in the context of the medieval Welsh prose romance Peredur Son of Efrog, part of the collection of medieval Welsh tales called the Mabinogion. The provenance of the original tale has been widely debated as it survives in four versions and has parallels both with French literature (most notably Chrétien de Troyes's Perceval) and native Welsh storytelling tradition. This article focuses on the visual insets present in the medieval tale and Jones's text, and demonstrates that the complex network of intertextual relationships between the multiple versions of "Peredur," along with the trends in the academic debate centred around it, is reflected in Jones's novel by means of the compositional devices characterised by the oscillation between the verbal and the visual.
\end{abstract}

Keywords: Welsh writing in English; Cynan Jones; Bird, Blood, Snow; Mabinogion; Peredur.

Cynan Jones's novel Bird, Blood, Snow (2012) is part of the New Stories from the Mabinogion series comissioned by the Welsh publisher Seren. The collection offers modern rewritings of the medieval Welsh tales known as the Mabinogion, Jones's novel being a reworking of Peredur Son of Efrog, one of the three tales classified as rhamantau-"Welsh romances." The tale is the story of Peredur [Perceval] who leaves his mother to join Arthur and his knights. Having earned the status of a member of Arthur's court, he embarks on a number of quests to eventually become the consort of the Empress of Constantinople and defeat the witches of Caerloyw. Set in twenty-first-century Wales, Cynan Jones's adaptation is a collage-like amalgam of disparate narrative voices, intertextual allusions and intermedial (mostly pictorial) elements.

Aleksander Bednarski, PhD, The John Paul II Catholic University of Lublin, Institute of Literary Studies, Department of Celtic Studies; address for correspondence: Al. Racławickie 14, 20-950 Lublin, Poland; e-mail: alekbednarski@gmail.com. 
My aim in this paper is to examine a selection of the visual elements the novel abounds in and explore the ways they are used to transfer the medieval story into modern form. It should be noted at the outset, however, that the scope of the present paper must remain limited. A comprehensive analysis of Jones's novel that takes into account its pre-text poses a serious methodological challenge, as the problems involved include at least several fields: intermedial elements in contemporary fiction, Celtic Studies, medieval folklore and literature (Welsh and French) as well as paleography and psychology. In what follows, I will therefore narrow my analysis to the main issues brought up in the debate on "Peredur" and the visual insets shared by the medieval tale and Jones's novel.

Being an adaptation of another narrative, Bird, Blood, Snow naturally invites an examination from an intertextual perspective. However, since my analysis focuses on the novel's visual elements, it is necessary to adopt a theoretical framework that would embrace both aspects. Such a framework is provided by the approaches that stress the affinities between intermediality and intertextuality, seeing the former as "an umbrella term that includes intertextuality" (Wagner 379). For Hans Lund, in turn, interactions between texts in any media come under the aegis of intertextuality, so that "verbal and visual texts function in an intertextuality" (9). For the sake of clarity and following Irina O. Rajewsky (2005), I propose to divide the possible relationships between texts into intermedial and intramedial. The latter would refer to relationships within the same medium (e.g., literary text-literary text, film-film), so that intertextuality would mean "references by a (literary) text either to individual other texts or to literary (sub)systems" (Rajewsky 54). ${ }^{1}$ The term intermedial would thus be reserved for relationships between texts composed in different media (i.e., different semiotic systems like music and literature, painting and film etc.). The intermedial category can be variously subdivided, and for the present purpose I choose to follow the schematisation proposed by Hans Lund who provides categories for all visual insets present in Bird, Blood, Snow. Thus, illustrations fall under the category of

\footnotetext{
${ }^{1}$ Although the intermedial elements in Jones's novel are central to my concerns, its intratextual relationships with Peredur still constitute an important context for the present analysis. When referring to intertextual relationships, I will use the basic terms developed by Gérard Genette: hypotext/hypertext, the source text and the adaptation respectively (Genette, Palimpsests 5), and paratext - the "threshold" or "vestibule" between the text and the world at large (Genette, Paratexts 2). Paratext is further divided into peritext (elements that are part of the published text, e.g., titles, prefaces, illustrations, blurbs), and epitext - elements located outside the text, e.g., interviews with the author (Genette, Paratexts 3-5).
} 
'combination', where two or more media are present directly, i.e., bimedial communication, typography is the domain of 'integration' where the element in one medium cannot be removed from the other "without destroying the verbal structure" (as in, e.g., concrete poetry), and verbal references to the image are examples of 'transformation' which involves only one medium (Lund 9). Transformation (unimedial communication) itself is subdivided by Lund into ekphrasis and iconic projection.

Ekphrasis has been the subject of a lively debate that, to date, has generated a large body of diverse and sometimes overlapping conceptions and even a brief overview thereof is beyond the scope of this paper. As Lund's definetion of ekphrasis is too narrow for my purposes, ${ }^{2}$ I follow Claus Clüver's understanding of ekphrasis as "the verbalization of real or fictitious texts in a non-verbal sign system" (49, emphasis in the original), which makes possible the inclusion of, e.g., descriptions of TV or video footage present in Jones's novel. In the context of the intense intertextual relationship between Bird, Blood, Snow and its hypotext, it is also important to bear in mind that ekphrasis (however defined) may also be understood as a way of intermedial quoting, with the verbal medium functioning as a frame (Yacobi, "Fictive" 70).

Iconic projection, in turn, is Lund's term for "texts describing and/or interpreting the outer reality qua picture" (16). Iconic projection is different from such categories as by, e.g., "painterly effect," in that it involves what Lund calls an aesthetic distance which demarcates the sphere of the picture in the manner of a theatre stage (71). This may be achieved either by material frames within the diegetic reality (e.g., a description of a window view) or any immaterial border that delimits "the field of vision as unity structured as a picture" (Lund 197). Thus, a structured picture is mediated by an observer within the text-a narrator or a character (Lund 197). As in the case of ekphrasis understood as a verbal frame, iconic projection may also be seen as a type of intermedial quotation, although the ontological status of such a picture is, of course, different from the ekphrastic.

The theoretical apparatus outlined above must be supplemented by yet another aspect of pictorial transformation which affects the compositional plane of the text, i.e., imitation. This is the case when, in Wolfgang Hallet's words, "the literary text mimics the macro-structure of the referenced medium and adopts its compositional principles or aesthetic structure" (608). One variation of such a mechanism which is particularly pertinent to the present analysis is

\footnotetext{
${ }^{2}$ For Lund, ekphrasis covers "texts describing and/or interpreting real or fictitious pictures" (16).
} 
Murray Krieger's concept of "ekphrastic principle." Although Krieger's point of departure is ekphrasis (he actually defines ekphrasis as "the imitation ... of a work of plastic art" (265)), and although his analysis is limited to poetry, his model, in fact, bears all the hallmarks of structural imitation as defined by Hallet. According to Krieger, a successful poem depends on its achieving "a formal and linguistic self-sufficiency" which, in turn, is understood as the creation of "the sense of roundness" (263). The resulting circularity imbues the poem with the qualities of a plastic/spatial work of art and the impression of arrested temporality. The process is, of course, conditioned by an ekphrastically described objet d'art which lends the poem its structure, so that the text "shape[s] itself in the form of its content" (Krieger 269). As I will try to demonstrate, in Bird, Blood, Snow the place of the ekphrastically described objet d'art is taken by an iconic projection, but the mechanism remains essentially the same. Inscribed in Krieger's conception of ekphrastic relationships is also the old debate over the sameness or rivalry between literature and painting. The former stance has been the domain of the ut pictura poesis tradition going back to Horace, while the latter characterises the paragone - the competition between the arts, which reached its climax in Gotthold Lessing's division between the spatiality of the painting and the temporality of poetry (Rippl 4).

Having established the basic theoretical framework for intermedial analysis, we may now turn to the hypotext of Jones's novel-Peredur Son of Efrawg. It has been described, along with the other two "romances" in the Mabinogion, as the most sophisticated example "of imaginative writing in Middle Welsh prose" (Roberts, "Tales" 225), but also as "a microcosm of all the problems which can be found in early Welsh prose literature" (Lovecy 171). An exhaustive presentation of the formidable historico-literary problems posed by the tale goes far beyond the limits of the present paper, but even a cursory look at the debate concerning "Peredur's" provenance, transmission and structural integrity shows, despite the many interpretative avenues probed by scholars over the last century or so, that it is characterised by a considerable degree of inconclusiveness and indeterminacy.

Perhaps the most highly contested issue is that of which version of the tale could be described as "definitive." Peredur survivies in four manuscripts, Peniarth 7 and Peniarth 14 (both c. 1275-1325), which contain only parts of the story found in two other manuscripts: the White Book of Rhydderch (1300-1350) and the Red Book of Hergest (late 14th century). The question of whether the longer versions are complete or merely expanded remains, however, 
open: the differences between the versions within each pair and the crossrelationships between them make any satisfactory conclusions concerning the chronology and provenance of individual versions extremely difficult to arrive at. The manuscript tradition, as Lovecy admits, "is virtually impossible to unravel" and the authoritative text "difficult to settle upon" (171).

The problem of the definitive version is complicated by the evident affinities between some sections of the Welsh versions of Peredur and Chrétien de Troyes's Perceval ou le conte du Graal (c. 1181-1190). The conundrum of determining the direction of influence between the Welsh and French texts has not been satisfactorily resolved, and is known in Celtic Studies as the $\mathrm{Ma}$ binogionfrage (Roberts, "Peredur" 58). To make things even more complicated, as Cerdiwen Lloyd-Morgan has shown, the tale also betrays traces of the influence of French romances other than Chrétien's ("Y Cyd-destun" 121-125). Be that as it may, the Welsh story definitely cannot be regarded as a mere translation or retelling of Chrétien's Perceval, but a far-going adaptation that remains "stylistically and structurally within the Welsh narrative tradition" (Davies xi). This, in turn, makes the label rhamant "both misleading and inappropriate" (Davies xi), or at least "superficial" (Lloyd-Morgan, "Medieval" 57), so that Peredur remains, in a sense, a generic hybrid. Another area for speculations is the attempts to trace the hypothetical ur-text of the tales. Will Parker locates the common source in early twelfth-century Wales, while other scholars opt for a common French-language source (Koch 1649). As Andrew Breeze has demonstrated, however, the extant versions can hardly predate 1200 due to the reference to windmills, which are not attested in England before 1170 (59).

Structurally, Peredur is frequently seen as "incohesive" (Roberts, "Tales" 225) and, compared with Chrétien's Conte du Graal, "a failure" (Lovecy 180). The chief fault of the longer versions, according to critics, is the ending, which is abrupt and leaves many threads and episodes unexplained (Roberts, "Tales" 228, Lloyd-Morgan, "Narrative" 195). ${ }^{3}$ Attempts have been made, however, to look for structural unity by uncovering mythological themes from the layers of accretions: Glenys Goetinck, for instance, argues that the underlying framework is provided by the sovereignty myth (Lloyd-Morgan, "Medieval" 188). For Lloyd-Morgan, the very idea of the quest for a buried unity rests on the false premise that successful narratives should unfold as a linear sequence of

\footnotetext{
${ }^{3}$ The problem of the ending also concerns other versions of Peredur's story: Chrétien's version remains unfinished, just like some of his Continuators' (Lloyd-Morgan, "Y Cyd-destun" 116).
} 
events ("Medieval" 189). Instead, she proposes that the inconsistencies and non-sequiturs in the tale in fact form an interlacing pattern that reflects the conventions of the oral storytelling tradition in which what mattered more than interconnections on a deeper level was "the plot or pure narrative" (Lloyd-Morgan, "Medieval" 230). A similar stance is taken by Brynley F. Roberts, although only in relation to the Peniarth 7 version, which he reads as more firmly rooted in the native Welsh oral tradition. According to him, what the modern reader sees as unexplained loose ends might have referred to a larger body of the Peredur material which the cultural milieu was well familiar with (Roberts, "Peredur" 70). In fact, Roberts sees the shorter and longer versions as two stages in the process of transition from the mode rooted in native Welsh oral storytelling (whose traces he identifies in the shorter versions), and the more modern, rationalising attitude in the longer ones, hence the title of his 2000 article. Parker, in turn, points to several other themes implicit in the story, i.e., the tension between pagan and Christian themes as well as Welsh dynastic tensions reflected in the theme of regicide and omertà. Stephen Knight, in turn, reads the tale in the light of postcolonial theory, interpreting Peredur as "a hybridized syncretic dialogue with the culture of the colonizer" (i.e., the Normano-French) and, as such, being "replete with indeterminacy" (147).

Another significant aspect of Peredur is the particularly pronounced role of the redactors, whose effort to transfer the text into writing in some cases casts them in the role of co-authors. Furthermore, the "Peredur debate" itself, with a long history of its own, seems to mirror the "branching" and unstable structure of the tale. Thus, Peredur is an indeterminate text in terms of the underlying mythological material, structure, historico-cultural background, authorship, intertextuality, as well as meta-textuality.

Before moving on to the novel, it is necessary to briefly consider the blood-drops scene in Peredur which involves the crossing of the verbal-visual boundary and on which the present analysis of Jones's novel is centred. The original scene can be categorised as an iconic projection and is a moment of stasis and contemplation. It takes place when Peredur leaves the hermit's cottage and meditates over a dead duck on white snow, contemplating the contrasting colours and comparing them to the "woman he loved best" ("Peredur" 79). ${ }^{4}$ Thus, the hero "projects" the girl's portrait onto the palette of

\footnotetext{
${ }^{4}$ The woman "portrayed" by Peredur has not been identified as any of the many maidens Peredur meets on his way.
} 
colours extrapolated from the physical objects he is seeing. Peredur's contemplative reverie is then ruthlessly interrupted by Arthur's knights, which triggers his violent response. The distance, which is the condition for the iconic projection to occur, takes the form of Peredur's own retrospective account of his moment of contemplation when he later describes the meditation to Arthur and his knights, explaining his reaction ("Peredur" 81). It is important to realise that the episode involves the following pattern: the description of a fragment of fictional reality qua picture, and the suspension or slowing down of the narrative flow, which is then abruptly interrupted and the story resumes. ${ }^{5}$ In Mabinogion studies, to my knowledge, the scene has not been discussed in terms of its pictoriality. However it might be interpreted, it certainly highlights an underlying conflict which is partially expressed intermedially. As I will try to demonstrate below, this pictorial cluster (the contemplation of an image interrupted by an agent of the pro-narrative tendency) constitutes the compositional kernel of Bird, Blood, Snow.

In intertextual terms, Jones's novel closely follows the sequence of events in the original story. Peredur's mother moves to a holiday village from a derelict post-industrial estate, but her son is soon drawn to children's gangs that use sticks and bikes to wage war against other neighbourhoods. Peredur quickly reveals his extraordinary strength and fighting skills, as well as his inability to control his aggression. Notorious for violence which results in life-threatening injuries to his opponents, Peredur is placed first in foster care, then a children's home and, eventually, in psychiatric hospital where, already a grown man, he massacres the nurses whom he takes for witches. Arthur (the alleged leader of a gang) remains Peredur's "holy Grail" — a myth created in his own imagination.

The significant motifs in Jones's rewriting of the original tale are the attempts to explore Peredur's personality and understand the psychological mechanism behind his outbursts of violence, and to provide a comprehensive reconstruction of his story. The first motif is expressed by the actions taken by doctors (e.g., by giving Peredur the Rorschach test) and by the narratorsthe author of a literary account of Peredur's life, whose narrative comes in extracts from his/her unfinished manuscript (A), and another author-redactor responsible for collecting and arranging the available material (B), which is,

\footnotetext{
${ }^{5}$ Another example of iconic projection occurs when Peredur sees the Empress of Constantinople in the window of her "pavilion" (92). The hero continues to gaze at the woman for nearly three days, which again generates a sense of arrested time. This time, his contemplation of the "picture" is interrupted by a blow on his back delivered by the miller.
} 
in fact, a conglomerate of micro-narratives by different voices. B's role and method are revealed in his or her letter to the editor which makes up the first section of the novel that, however, comes before the title page. Interestingly, the afterword and the acknowledgements section are followed, untypically for Seren's Mabinogion series, by an appendix with an article from the fictional newspaper Celtic Echo. Thus, the fictional reality "intrudes" into the novel's peritext thereby blurring the border between the fictional and authorial voices. I will return to the appendix later: for now, it is important to stress that the collage-like composition of the novel alone reflects the multiplicity of redactions of the original story and its textual and structural instability.

In Jones's retelling, the scene corresponding to the blood-drops episode comes as part of an anonymous "unfinished manuscript." The original hermit is a paedophile who coaxes young Peredur to spend a night in his bungalow (whether or not the man harasses the boy remains untold). ${ }^{6}$ Upon leaving the bungalow the following morning, Peredur sees a dead duck in the snow and a jackdaw attracted by the carcass (Jones 84). The wording of the iconic projection imitates the original - the colours also remind Peredur of "the woman he loved best" and the framing of the scene is doubled. The descripttion of the boy's trance is followed by an abrupt change of narrative perspective, as it is commented upon by A, who tries to interpret Peredur's mind in psychological terms, and the next section brings yet another shift of the point of view-it is retold (supposedly) by Gwalchmai. As in the original, Peredur's violence is triggered by Kay - a member of the bicycle gang who interrupts the hero's contemplation.

A significant difference between the original and Jones's version is that Peredur's reverie is followed by a description providing an insight into his mind. The urge to join Arthur "mixes and toils" with the images of the woman and his mother, which is explicitly identified by A as "an internal conflict" (Jones 85). What is significant in the context of the present analysis is that the conflict can also be understood in terms of the paragone: "sentences and images [in Peredur's mind] fell into a great toil" (Jones 85).

In Jones's text, the pictorial clusters are thus explicitly linked to Peredur's internal world, which can be associated with the visual. Peredur himself describes it as his "world of magic" (Jones 160) and his "special place" where "everything is fine" and "the real things blur" (Jones 167). He is also credited

\footnotetext{
6 "The bungalow of the hermit was protected by some spell, for we lose sight of our hero and thus what happened that night is unclear" (Jones 84).
} 
with a vivid visual imagination in one of the medical reports (Jones 147). Interestingly, the hero's violent behaviour seems to be triggered by the violation of the border between those realities, e.g., the attack on Kay after he interrupts Peredur's contemplation of the dead duck, or the massacre of the nurses caused by other patients' talking. ${ }^{7}$ It would be thus tempting to read this tension as the paragone - the rivalry between the visual/spatial and the verbal/temporal. In this model, the verbal would stand for the attempts to maintain the cohesion of the narrative (on the level of the redactors) and to semiotise Peredur's internal conflicts and solve the problems posed by the narrative(s) (on the level of the academic debate).

Before arriving at more specific conclusions, however, it is necessary to examine the arrangement and treatment of other visual insets which, as we will see, mirror the pictorial clusters discussed above. A more complex arrangement of intermedial framing can be found in the most robust variation of the pictorial cluster - the fragment where Peredur is examined with the Rorschach test. The section provides Peredur's responses to inkblots on three cards (IV, VI, II), each reproduced twice (turned and unturned) in black and white. Thus, blot IV is interpreted as a dog (unturned) and a dragon or a shield (turned), blot VI as a vagina (unturned) or a lakeside bank (turned), and blot II as witches (unturned) or a witch bleeding to death (turned). The section is followed by a note by $\mathrm{A}$ who provides an additional ekphrastic description of the inkblots: "[It could only make black and white copies; on the test there are blotches of red around the 'feet' (low, where the two shapes join as the card is upright), and the 'heads' are red and the 'necks' pinkish.]" (Jones 146). It is significant that in his/her ekphrasis of the blots he/she describes the original colour images on the basis of the reproduced black and white copies of them. Thus, the colour images, to which Peredur responds remain absent and are, in fact, framed by the black and white copies which are, in turn, framed by A's ekphrasis. Peredur's responses refer to the absent colour inkblots and are merely illustrated post factum by the intereference of A, who is responsible for tabulating them. This complex arrangement of frames can be presented as follows: the original colour image/Peredur's "contemplation" of it (the image - the verbal frame) - the copy of the image/A's comment, the latter pair corresponding to the the retrospective description of Peredur's trance. Thus, the Rorschach section retains the essential structure of the pictorial

\footnotetext{
7 "I dedicate this to her. They were talking through your music, maiden. And we cannot have that" (Jones 168).
} 
cluster. Additionally, A's arrangement of the black and white copies side by side with Peredur's responses may be seen as a representation of the pro-narrative tendency in the text. As such, A might be seen as the agent of the verbal, dominating the visual by the sheer process of framing (as Yacobi notes, the borrowed inset "behaves within its new environment like any other material represented in the text: it necessarily follows the rules and goals of the operative (linguistic) frame" ("Fictive" 71)). The whole section would then acquire a paragonal tension.

Another point of comparison we might make here between Jones's text and the problems related to Peredur is the psychological aspect of the Rorschach section which makes the desire to penetrate Peredur's mind particularly pronounced. As Lloyd-Morgan notes, one of the main differences between the Welsh tales and Chrétien's version (and continental romance in general) is the stress put on the exegetical aspect of the latter, manifested in the meticulous analysis of feelings and ideas. This feature is absent from the Welsh versions, which are interested more in the story (Lloyd-Morgan, "Medieval" 5). The attempt to penetrate Peredur's unconsciousness by means of the Rorschach test and the multiple bordercrossings between media may be seen as echoing the co-presence of, and friction between, two disparate tendencies in the Welsh versions: the native Celtic/Welsh tradition with oral roots on the one hand, and the written continental courtly romance on the other.

The structure of the Rorschach episode is a microscale version of that which, on the macroscale, functions as the organising principle of the whole novel: the flickering across the verbal-visual divide. The scene that deserves special attention in this context is the one corresponding to the killing of the witches of Caerloyw set in the psychiatric ward. Its significance stems from it being part of the frame binding the main body of the novel, thereby transferring the intermedial relationships we have observed in the cluster and the Rorschach section onto the macro-compositional plane. Thus, in the last scene before the synospis of "Peredur," the afterword and the appendix, Peredur locks himself in one of the rooms with the nurse whose throat he has just cut, while what is presumably the hospital personnel or the police are trying to force the door open. The section, however, cuts off in mid-sentence: "They are trying now with chairs; it's funny, the strange vibrating noise of them bouncing off. The blue lights and the noise" (Jones 179) to be taken up by the section that comes immediately after author-redactor B's letter at the beginning of the novel: "all look distant from behind the glass" (Jones 14). On closer inspection, the framing scene is in fact a re-staging of the blood-drops 
episode: Peredur looks at the nurse dying and the canister with gas thrown in through the skylight: "I look down at the black canister, strange bird bust through that window, and at the white ground and at the red blood, thinking of the woman that time, the bird dead in the snow" (Jones 14). All the components of the pictorial cluster remain essentially the same: the projected image in the form of a tableau vivant ${ }^{8}$ and the breaching of the boundary of Peredur's "magic world" by the gas canister and the people forcing the door. In compositional terms, the splitting of the scene bestows a circular structure ('roundness') on the main body of the narrative, which, according to Krieger's conception of the ekphrastic principle, invests the text with the spatial qualities of a plastic objet d'art. The circular structure would then be the novel's unifying principle, binding the scattered narrative voices into a framed whole and thus echoing Peredur's "pictorial trance."

The sense of roundness imparted by the circular structure is, however, "sabotaged" by the aforementioned appendix which intrudes into the peritext. As mentioned earlier, the appendix is an article from Celtic Echo reporting several cases of dead sheep killed in remote areas of Wales by what is speculated to be a big cat. Photographs of the mutilated animals are shown to experts and farmers who suggest, however, that the sheep have been killed by something other than a big cat (for the reader, the implication of Peredur being responsible for it is clear). The appendix may be read in the light of the sheep episode in the original tale, in which black sheep join a white flock, turning white, and vice versa ("Peredur" 89). In the Celtic Echo article, the sheep may be taken to symbolise the intermedial oscillation which, as we remember, has been interpreted as crossing the borderline between Peredur's inner world and reality. The killed sheep could symbolise the tendency inscribed in the text figured by Peredur to resist this mechanism. The tendency is counterbalanced, however, by the ekphrases of the photographs which activate the intermedial fluctuation. Thus, the appendix is structured around the pictures whose polysemy (both sensu Barthes and in the context of the diegetic reality) precludes any definitive conclusions. The ekphrases, being in fact interpretations that retain or add information to the picture (Kafalenos 29-30), mirror the reader's reception of the novel's final section as an open ending. As such, the appendix cancels out the circular composition by providing an additional narrative segment which extends the fictive arena beyond the main body framed by the dying nurse scene(s). The section then echoes

\footnotetext{
${ }^{8}$ Or an attempted (the nurse is still alive) tableau mort/still life.
} 
the problematic or absent ending(s) not only of Peredur, but also its French counterparts. On the other hand, the indeterminate ending that destabilises the circular structure of the main body of the text seems to tap into the expectations of medieval audience who, as Lloyd-Morgan and Roberts assert, "would accept that adventures could be left unfinished and questions unanswered" (LloydMorgan, "Medieval" 49), and "may have been able to live with loose ends and unexplained mysteries in a way which modern readers find difficult" (Roberts, "Peredur" 70).

As can be seen, the open-endedness of Bird, Blood, Snow rests to a considerable extent on the oscillation between visual insets and their verbal framing. The series of Chinese boxes, each based on a similar pattern, has been revealed to be ultimately largely centered around the 'ur-image' of Peredur's beloved one as projected originally in the blood-drops episode. What seems to be semiotised is the border between the two media and its violation, which has been read as attempts to penetrate and control Peredur's inner world. Inscribed in the text, then, is the friction between two tendencies, the contemplative and the pro-narrative, which, on a purely literary level, can be taken to mirror the perennial paradox of word-image relationships manifested in the opposition between spatiality and temporality. What seems to be at play in Jones's novel is the aesthetic strategy founded on the 'productive conflict' of these two forces expressed by the constant violation of medial borders. While the narrativising capacity of ekphrasis has been amply demonstrated by Yacobi ("Pictorial"), the compositional mechanics of Bird, Blood, Snow indicates that iconic projection betrays a similar potential: Peredur, despite his inclination to lock himself in his visual 'inner sanctum', is credited by the medical report based on his Rorschach test results with "complex pictorial response suggesting capacity to build story" (Jones 148, emphasis mine). Additionally, the roundness achieved by the splitting of the final/opening scene, although not unusual in prose fiction (e.g., Finnegans Wake), invites further attention from the point of view of spatiality in literature, by raising questions concerning the possible applications of the ekphrastic principle in non-poetic texts.

In the context of the novel's hypotext, the two tendencies echo the problems inherent in Peredur itself, as well as in the debate surrounding it. In the former case, it is the amalgam of two literary and cultural traditions in the Welsh narrative(s) (Celtic/Welsh and continental/French) and the tensions stemming from the alleged sovereignty motif or the pagan-Christian/Arthurian dichotomy. Structurally, the recurrence of the segments based on the similar 
arrangement of intermedial framing chimes well with the use of repetitions and the interlace structure of the medieval text. In metatextual terms, in turn, the friction can be said to correspond to the tale's resistance to the attempts to "contain" it, i.e., to impart a structure on an otherwise incoherent story (on the compositional-editorial plane). ${ }^{9}$

In more general terms, the "portrait" of the unidentified woman which constitutes the novel's structural kernel may be seen as the concretisation of all the enigmas posed by the medieval tale. In his discussion of iconic projection, Hans Lund notes that words and pictures, constituting two different systems, "communicate messages which demand different kinds of thinking from the receiver" (200). The iconic projection of "the woman he [Peredur] loved best" may be seen as a symbolically-charged figure for what are probably insurmountable and untranslatable divergencies between the expectations of the medieval audience, their cultural mindset and the "canvas of tradition" (Roberts, "Peredur" 70).

Considered in its own terms, without the context of its hypotext (as posited by Lloyd-Morgan in the case of Peredur), Jones's novel, due to the wide gamut of visual insets ranging from transformation and integration to combination, could well be examined in the wider context of the experimental trend in modern fiction variously defined as the multimodal novel, hybrid texts or liberature (cf. Maziarczyk). This property of Bird, Blood, Snow demonstrates its interconnectedness with the broader trends in literature at large and, in terms of its use of intermedial elements which are an exception rather than a rule in the context of Welsh writing in English, raises questions about the situation of this branch of Welsh literary production. One cannot but notice that even in this respect, as Lloyd-Morgan ("Y Cyd-destun") demonstrates, Bird, Blood, Snow also mirrors the interconnectedness between "Peredur" and the mainstream of contemporary European literary culture. Furthermore, the oscillation between the visual and verbal medium in the novel, alongside other compositional and intertextual aspects, which often results in blurring ontological planes, invites the problem of classification of the novel as modernist or postmodernist. According to the criteria proposed by Brian McHale, modernist fiction and postmodernist fiction are characterised by the episte-

\footnotetext{
${ }^{9}$ Not discussed here due to the lack of space, the tree-diagram on page 130 designed to help order the stages of the story (the plan in fact bears the heading "Might Be Of Help") is another manifestation of this tendency. Jones's map of the novel's storyline may be thought of as a distant analogy to the diagrams presenting the relationships between Welsh manuscripts containing versions of "Peredur" (Thomas 19-41).
} 
mological and ontological dominant respectively (9-10). While the dominant of Bird, Blood, Snow may be tentatively identified as epistemological, the text often "collapses" into the ontological boundary, so that Jones's novel could be described, to use Brynley Roberts's phrase, as a text in transition between the modernist and the postmodernist aesthetics.

For the reasons specified in the opening paragraph of this paper, in the present study I have been able to touch upon only a narrow area of intermedial problems presented by Cynan Jones's novel in relation to "Peredur Son of Efrog." Worth signalling are the typographic devices used in the text or the elements of music. Bird, Blood, Snow, along with other novels from the Seren series, would also benefit from a closer scrutiny from the point of view of their intramedial (intertextual) relationships and the use of the Rorschach inkblots may invite an interdisciplinary examination of the novel's psychoanalytic subtext. It would also seem that a consideration of unimedial visual elements in the medieval tale could open up possible avenues and perspectives in Mabinogion studies as well.

\section{WORKS CITED}

Breeze, Andrew. "Peredur Son of Efrawg and Windmills." Celtica, vol. 24, 2003, pp. 58-64.

Clüver, Claus. "Quotation, Enargeia, and the Functions of Ekphrasis." Pictures into Words: Theoretical and Descriptive Approaches to Ekphrasis, edited by Valerie Robillard and Els Jongeneel, VU UP, 1998, pp. 35-52.

Davies, Sioned. Introduction. The Mabinogion, edited and translated by Sioned Davies, Oxford UP, 2008, pp. ix-xxx.

Genette, Gérard. Palimpsests. Literature in the Second Degree. Translated by Channa Newman and Claude Doubinsky, U of Nebraska P, 1997.

Genette, Gérard. Paratexts: Thresholds of Interpretaion. Translated by Jane E. Lewin, Cambridge UP, 2001

Hallet, Wolfgang. "A Methodology of Intermediality in Literary Studies." Handbook of Intermediality: Literature - Image - Sound - Music, edited by Gabriele Rippl, De Gruyter, 2015, pp. 605-18.

Jones, Cynan. Bird, Blood, Snow. Seren, 2012.

Kafalenos, Emma. "The Polysemy of Looking: Reading Ekphrasis alongside Images in Calvino's Castle of Crossed Destinies and Vargas Llosa's In Praise of the Stepmother." Poetics Today, vol. 33, no. 1, 2012, pp. 27-57.

Knight, Stephen. "Resemblance and Menace: A Post-colonial Reading of Peredur." Canhwyll Marchogyon: Cyd-destunoli "Peredur", edited by Sioned Davies and Peter Wynn Thomas, Gwasg Prifysgol Cymru, 2000, pp. 128-47. 
Koch, John T. "Y Tair Rhamant." Celtic Culture: A Historical Encyclopedia, edited by John T. Koch, vol. 5, ABC-Clio, 2006, pp. 1647-51.

Krieger, Murray. "Appendix: Ekphrasis and the Still Movement of Poetry; or Laokoön Revisited (1967)." Ekphrasis: The Illusion of the Natural Sign, Johns Hopkins UP, 1992, pp. 263-88.

Lloyd-Morgan, Ceridwen. "Narrative structure in Peredur." Zeitschrift für celtische Philologie, vol. 38, 1981, pp. 187-231.

Lloyd-Morgan, Ceridwen. "Y Cyd-destun Ewropeaidd." Canhwyll Marchogyon: Cyd-destunoli "Peredur", edited by Sioned Davies and Peter Wynn Thomas, Gwasg Prifysgol Cymru, 2000, pp. 123-127.

Lloyd-Morgan, Ceridwen. "Medieval Welsh Tales or Romances? Problems of Genre and Terminology." Cambrian Medieval Celtic Studies, vol. 47, 2004, pp. 41-58.

Lovecy, Ian. "Historia Peredur ab Efrawg." The Arthur of the Welsh: The Arthurian Legend in Medieval Welsh Literature, edited by Rachel Bromwich, A. O. H. Jarman, and B. F. Roberts, U of Wales P, 1991, pp. 171-82.

Lund, Hans. Text as Picture: Studies in the Literary Transformation of Pictures. Translated by Kacke Götrick, The Edwin Mellen Press, 1992.

Maziarczyk, Grzegorz. The Novel as Book: Textual Materiality in Contemporary Fiction in English. Wydawnictwo KUL, 2013.

McHale, Brian. Postmodernist Fiction. Methuen, 1987.

Parker, Will. "Peredur ap Efrawg." mabinogion.info, 2010, www.mabinogion.info/index.html. Accessed 12 Mar. 2020.

"Peredur Son of Efrog." The Mabinogion, edited and translated by Sioned Davies, Oxford UP, 2008, pp. 65-102.

Rajewsky, Irina O. "Intermediality, Intertextuality, and Remediation: A Literary Perspective on Intermediality." Intermédialités, vol. 6, 2005, pp. 43-64.

Rippl, Gabriele. Introduction. Handbook of Intermediality: Literature - Image - Sound - Music, edited by Gabriele Rippl, De Gruyter, 2015, pp. 1-31.

Roberts, Brynley F. "Tales and Romances.” A Guide to Welsh Literature, edited by A. O. H. Jarman and Gwilym Rees Hughes, vol. 1, U of Wales P, 1992, pp. 203-43.

Roberts, Brynley F. "Peredur Son of Efrawg: A Text in Transition.” Arthuriana, vol. 10, no. 3, 2000, pp. 57-72. JSTOR, www.jstor.org/stable/27869564. Accessed 30 Sept. 2016.

Thomas, Peter Wynn. "Cydberthynas y Pedair Fersiwn Ganoloesol.” Canhwyll Marchogyon: Cyddestunoli "Peredur", edited by Sioned Davies and Peter Wynn Thomas, Gwasg Prifysgol Cymru, 2000, pp. 10-49.

Wagner, Peter. "The Nineteenth-century Illustrated Novel." Handbook of Intermediality. Literature - Image - Sound - Music, edited by Gabriele Rippl, De Gruyter, 2015, pp. 378-400.

Yacobi, Tamar. "Pictorial Models and Narrative Ekphrasis." Poetics Today, vol. 16, no. 4, 1995, pp. 599-649.

Yacobi, Tamar. "Fictive Beholders: How Ekphrasis Dramatizes Visual Perception." Iconotropism: Turning Toward Pictures, edited by Ellen Spolsky, Bucknell UP, 2004, pp. 69-87. 


\section{TEKSTUALNE METAMORFOZY: INTERMEDIALNOŚĆ \\ W PEREDURZE SYNU EFRAWGA I BIRD, BLOOD, SNOW CYNANA JONESA}

\section{Streszczenie}

Niniejszy artukuł jest analizą powieści Cynana Jonesa Bird, Blood, Snow w kontekście pisanego prozą średniowiecznego walijskiego romansu dworskiego Peredur syn Efrawga, który wchodzi w skład zbioru opowieści znanego jako Mabinogion. Proweniencja średniowiecznej opowieści jest przedmiotem ożywionej debaty: różniące się od siebie wersje zachowały się w czterech rękopisach, wykazują związki z literaturą francuską, w szczególności z poematem Chrétiena de Troyes Perceval, a jednocześnie pozostają mocno osadzone w walijskiej tradycji ustnej. Analizie poddane są elementy wizualne obecne zarówno w tekście średniowiecznym, jak i w powieści Jonesa, co pozwala na potwierdzenie sformułowanej we wstępie tezy, iż warstwa kompozycyjna powieści, oparta w dużej mierze na oscylacji pomiędzy słowem a obrazem, odzwierciedla nie tylko bogatą sieć powiązań intertekstualnych, w jakie uwikłany jest Peredur, ale również metatekstualny aspekt badań historyczno-literackich poświęconych średniowiecznemu tekstowi.

Słowa kluczowe: literatura walijska w języku angielskim; Cynan Jones; Bird, Blood, Snow; Mabinogion; Peredur. 